UCRL-JC-122274 Rev 1 PREPRINT

CONF-960772--17

\title{
Chemical Kinetic Modeling of High Pressure Propane Oxidation and Comparison to Experimental Results
}

\author{
D. N. Koert \\ W. J. Pitz \\ J. W. Bozzelli \\ N. P. Cernansky
}

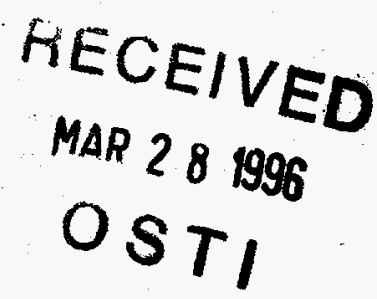

This paper was prepared for submittal to the 26th International Symposium on Combustion Naples, Italy

July 28-August 2, 1996

February 1996

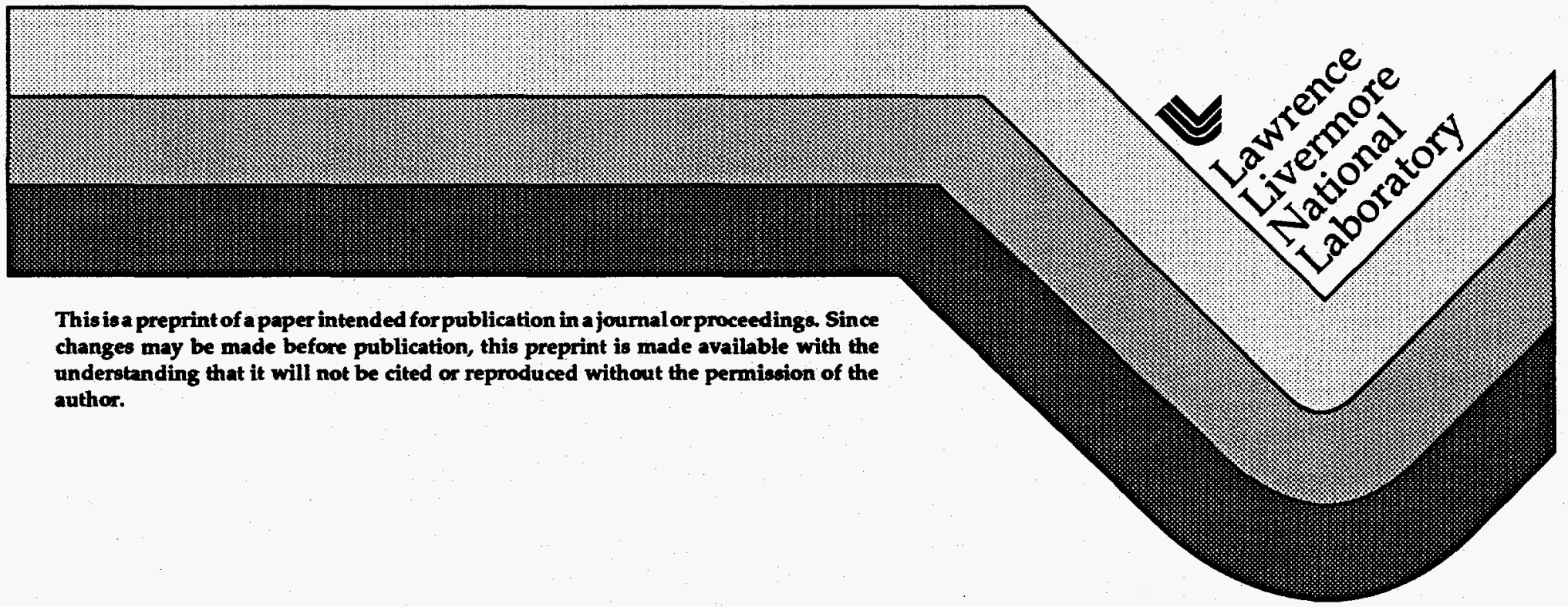


This document was prepared as an account of work sponsored by an agency of the United States Government. Neither the United States Government nor the University. of California nor any of their employees, makes any warranty, express or implied, or assumes any legal liability or responsibility for the accuracy, completeness, or usefulness of any information, apparatus, product, or process disclosed, or represents that its use would not infringe privately owned rights. Reference herein to any specific commercial products, process, or service by trade name, trademark, manufacturer, or otherwise, does not necessarily constitute or imply its endorsement, recommendation, or favoring by the United States Government or the University of California. The views and opinions of authors expressed herein do not necessarily state or reflect those of the United States Government or the University of California, and shall not be used for advertising or product endorsement purposes. 


\section{DISCLAIMER}

Portions of this document may be illegible in electronic image products. Images are produced from the best available original document. 


\title{
Chemical Kinetic Modeling of High Pressure Propane Oxidation and Comparison to Experimental Results
}

\author{
David N. Koert \\ Mechanical Engineering Dept., Wichita State University, Wichita, KS 67260 \\ William J. Pitz \\ Lawrence Livermore National Laboratories, Livermore, CA 94551 \\ Joseph W. Bozzelli \\ Chemistry and Chemical Engineering Department, New Jersey Institute of \\ Technology, \\ Newark, NJ 07102 \\ Nicholas P. Cernansky \\ Depart. of Mechanical Engineering and Mechanics \\ Drexel University, Philadelphia, PA 19104
}

January 18, 1996

Submitted to Twenty-Fifth International Symposium on Combustion Universita Federico II, Napoli, Italy

28 July -2 August 1993

Preference: Oral Presentation

Colloquium topic area: General Reaction Kinetics

Word count:

5406 total words $=2606$ text +2 figs @ 800 words +2 figs @ $400+$

2 tables@ 200 words

Corresponding author:

William J. Pitz, L-14

Lawrence Livermore National Laboratory

Livermore, CA 94551

phone: (510) 422-7730

fax: (510) 422-2644

email: pitz@llnl.gov 


\title{
Chemical Kinetic Modeling of High Pressure Propane Oxidation and Comparison to Experimental Results
}

\author{
David N. Koert \\ Mechanical Engineering Dept., Wichita State University, Wichita, KS 67260 \\ William J. Pitz \\ Lawrence Livermore National Laboratories, Livermore, CA 94551
}

Joseph W. Bozzelli

Chemistry and Chemical Engr. Depart., New Jersey Inst. of Tech., Newark, NJ 07102

Nicholas P. Cernansky

Depart. of Mechanical Engineering and Mechanics

Drexel University, Philadelphia, PA 19104.

\section{ABSTRACT}

A pressure dependent kinetic mechanism for propane oxidation is developed and compared to experimental data from a high pressure flow reactor. Experimental conditions range from 10-15 atm, $650-800 \mathrm{~K}$, and a residence time of $198 \mathrm{~ms}$ for propane-air mixtures at an equivalence ratio of 0.4 . The experimental results clearly indicate a negative temperature coefficient (NTC) behavior. The chemistry describing this phenomena is critical in understanding automotive engine knock and cool flame oscillations. Results of the numerical model are compared to a spectrum of stable species profiles sampled from the flow reactor.

Rate constants and product channels for the reaction of propyl radicals, hydroperoxy-propyl radicals and important isomers (radicals) with $\mathrm{O}_{2}$ were estimated using thermodynamic properties, with multifrequency quantum Kassel Theory for $k(E)$ coupled with modified strong collision analysis for fall-off.

Results of the chemical kinetic model show an NTC region over nearly the same temperature regime as observed in the experiments. Sensitivity analysis identified the key reaction steps that control the rate of oxidation in the NTC region. The model reasonably simulates the profiles for many of the major and minor species observed in the experiments.

Numerical simulations show some of the key reactions involving propylperoxy radicals are in partial equilibrium in this residence-time, temperature and pressure regime. This indicates that their relative concentrations are controlled by a combination of thermochemistry and other rate-controlling reaction steps. Major reactions in partial equilibrium include $\mathrm{C}_{3} \mathrm{H}_{7}+\mathrm{O}_{2}=\mathrm{C}_{3} \mathrm{H}_{7} \mathrm{O}_{2}, \mathrm{C}_{3} \mathrm{H}_{6} \mathrm{OOH}=\mathrm{C}_{3} \mathrm{H}_{6}+$ $\mathrm{HO}_{2}$ and $\mathrm{C}_{3} \mathrm{H}_{6} \mathrm{OOH}+\mathrm{O}_{2}=\mathrm{O}_{2} \mathrm{C}_{3} \mathrm{H}_{6} \mathrm{OOH}$. This behavior means that thermodynamic parameters of the oxygenated species, which govern equilibrium concentrations, are especially important. QRRK/fall-off results also show that the reaction of propyl radical and hydroperoxy-propyl radicals with $\mathrm{O}_{2}$ proceeds, primarily, through pressure-stabilized adducts, not chemically activated channels; thus dissociation and isomerization rates of these adducts are important. 


\section{INTRODUCTION}

The combustion of hydrocarbons in practical combustion devices such as internal combustion (I.C.) engines and gas turbines occurs at pressures well above atmospheric conditions where most experimental flame and thermal reaction studies are conducted. The development and validation of chemical kinetic mechanisms at appropriate pressures are needed to obtain accurate models of fuel oxidation rates in these combustors. Reaction mechanisms validated at these high pressures can then be applied to understand and to predict improvements in problems such as engine knock and hydrocarbon emissions. In this study, a pressure dependent kinetic mechanism for propane oxidation is developed and compared to experimental data from a high pressure flow reactor.

Experimental data from a pressured flow reactor (PFR) were used to validate the chemical kinetic mechanism. The PFR apparatus [1] complements other experimental apparatus (rapid compression machine, motored and fired I.C. engine) for the study of hydrocarbon oxidation related to automotive engine knock. A key advantage of the PRF is that the temperature, pressure and residence time of the fuel-air mixture are all well-characterized and controlled. The temperature history of the fuel-air mixture is maintained at a nearly constant, measured value. The effect of wall interactions on the gas-phase chemistry are also minimized in the PFR.

There is a significant amount of data in the literature on propane oxidation, but few investigations have reported data in a pressured flow reactor over the NTC region. One of the unique features of the PFR data [2] used in this study, is that it exhibits a clear and dramatic NTC region from $720-780 \mathrm{~K}$ that was not reported in other flow and stirred reactor studies [3-5]. These previous studies investigated propane oxidation at higher pressures, but focused on temperatures that exceeded the regime where NTC behavior is observed. NTC behavior has been observed in lower pressure studies of propane oxidation in static reactors [6].

In the following sections of the paper, the development of the chemical kinetic model is described and the experimental technique is documented. The results of the chemical kinetic model are compared to the experimental results. Finally, key findings from the kinetic modeling study are discussed. 


\section{CHEMICAL KINETIC MODEL}

The chemical kinetic mechanism was based on previous studies [7], with substantial improvements being made. As will be shown later, many of the important reactions involving alkylperoxy and related species are in partial equilibrium, so that it is essential to address properly the thermodynamic properties (enthalpy and entropy) of the species that control the equilibrium. Thermodynamic properties listed in Table 1 for the relevant radicals and stable parents were obtained by group additivity using THERM [8] with updated $\mathrm{H} / \mathrm{C} / \mathrm{O}$ groups and bond dissociation groups [9]. Abinitio calculations and isodesmic reaction analysis were performed for selected peroxides [10]. The thermochemical data allow accurate calculation of reverse reaction rate constants by microscopic reversibility.

The rate of decomposition of hydrogen peroxide is critical in controlling the location of the end to the NTC region, as discussed later. We use the recent rateconstant expression of Marinov et al. [11] which gives a nine parameter, pressure dependent fit. Use of this reaction rate expression improved the agreement between the measured and calculated propane consumption at the end of the NTC region.

The propyl peroxy and hydroperoxy-propyl [12] isomerizations are important reactions controlling the chemistry of the NTC region. The activation energy $\left(E_{a}\right)$ for the forward rate of these reactions is estimated by,

$$
\mathrm{E}_{\mathrm{a}}=\text { ring strain }+\mathrm{E}_{\mathrm{abst}} \begin{gathered}
\text { primary } \\
\langle\text { secondary }\rangle \\
\text { tertiary }
\end{gathered}+\Delta \mathrm{H}_{\mathrm{rxn}}
$$

where $\Delta \mathrm{H}_{\mathrm{rxn}}$ is the enthalpy of reaction (only included if reaction is endothermic). The ring strains are $6.0,0.1$, and $6.0 \mathrm{kcal} / \mathrm{mole}$ for heterocyclic rings (including peroxy moiety) containing five, six, and seven members respectively [13]. The ring strains were validated with comparisons of modeling and experimental results on the ethyl $+\mathrm{O}_{2}$ reaction system [14] and by ab initio calculations. The activation energy for abstraction ( $E_{\text {abst }}$ ) was estimated from the reverse reaction (exothermic direction). The reverse reaction is assumed to have an $E_{a b s t}$ which is the same as an alkyl radical abstracting an $\mathrm{H}$-atom from a propylhydroperoxide, 


$$
\mathrm{CCCOOH}+\mathrm{R} .=\stackrel{4}{\mathrm{CCCOO} .}+\mathrm{RH}
$$

where $\mathrm{R}$ is an alkyl radical. The activation energy of this reaction was estimated from an Evans-Polanyi plot ( $\mathrm{E}_{\text {abst }}$ versus $\Delta \mathrm{H}_{\mathrm{rxn}}$ ) [15] of the similar $\mathrm{H}$-atom abstraction reaction, $\mathrm{RH}+\mathrm{R}^{\prime}{ }^{\prime}=\mathrm{R} .+\mathrm{R}^{\prime} \mathrm{H}$. A reduction of $0.3 \mathrm{kcal} / \mathrm{mole}$ in $\mathrm{E}_{\mathrm{abst}}$ for each $\mathrm{kcal} /$ mole reduction in $\Delta \mathrm{H}_{\mathrm{rxn}}$ was obtained.

Pre-exponential factors for the $\mathrm{RO}_{2}$ isomerization were obtained using RADICALC [16], a computer code which implements transition state theory. The pre-exponential factors were validated from detailed model comparisons to experimental results on ethyl, tert-butyl, iso-butenyl and neo-pentyl radical reactions with $\mathrm{O}_{2}$. Results of the calculations show that the loss of internal rotors is the major contribution to the loss of entropy and thus reduction in Arrhenius preexponential factor with increasing ring size in the transition state. The rate constants of $\mathrm{RO}_{2}$ isomerization are given in Table 2 .

Rate constants and product channels for the reaction of propyl and hydroperoxy-propyl radicals with $\mathrm{O}_{2}$ and the reaction of important adducts were estimated with multifrequency quantum Kassel Theory (QRRK) $[17,18]$ for $k(E)$ coupled with modified strong collision analysis for fall-off.

The numerical model assumed constant temperature and pressure, and plug flow, in the flow reactor experiments.

\section{EXPERIMENTAL TECHNIQUE}

The Pressured Flow Reactor (PRF) has been described previously [2] and is only summarized here. A $2.5 \mathrm{~cm}$ diameter Vycor reactor is housed in a stainless steel pressure vessel. Reactant gases are metered with mass flow controllers. The experiments covered a range from $650-850 \mathrm{~K}$ and pressures of 10 and $15 \mathrm{~atm}$. for a residence time of $198 \mathrm{~ms}$. Propane/air mixtures were maintained at an equivalence ratio of 0.4 . The initial concentration of propane and oxygen was the same in each experiment $\left(2.47 \mathrm{~mol} / \mathrm{m}^{3}\right.$ at $\left.800 \mathrm{~K}\right)$, with the balance of the flow consisting entirely of nitrogen.

Samples of the reacting gases were withdrawn with a glass-lined, water-cooled gas sampling probe. Samples were extracted at constant residence time (198 ms) at different reactor temperatures by adjusting the axial position of the sampling probe 
during the experiment. Samples were analyzed on a Varian 3740 gas chromatograph (GC) with a Porapak $Q$ column followed by a Porapak $\mathrm{N}$ column and a flame ionization detector (FID). A postcolumn heated catalyst consisting of powder nickel was used to methanize the oxides of carbon to increase the sensitivity of their measurement by FID.

\section{RESULTS}

The results of the numerical model are compared to the experimentally measured results in Figs. 1-3. Figure 1 shows the propane consumption across the NTC region at 10 and $15 \mathrm{~atm}$. Both the model and experiments show a distinct NTC region. The characteristic shape of the profiles is well reproduced by the model.

Intermediate species profiles are shown in Figs. 2 and 3. The measured and calculated carbon monoxide profiles agree quite well. For those reactor temperatures that the measured and calculated propane consumption agreed (Fig. 1), the $\mathrm{CO}$ concentrations agreed as well. The calculated peak of the propene profile in excellent agreement at $10 \mathrm{~atm}$ (Fig. 2) and $15 \mathrm{~atm}$ (Fig. 3). The main reactions producing propene are discussed below. The predicted maximum concentration of formaldehyde is 3.5 and 15 times high at 10 and $15 \mathrm{~atm}$ respectively compared to the measured values. The acetaldehyde peak concentration is a factor of 3 high at 10 atm and $15 \mathrm{~atm}$ compared to the measured concentration. The carbon dioxide profiles are in good agreement at both pressures.

A number of minor species were measured and compared to calculated values. Methanol is predicted to be a factor of 5 higher than observed in the experiments. The calculated maximum concentration of acrolein is about 20 times higher than the measured maximum. The peak concentration of propene oxide is a factor of 2 low at $10 \mathrm{~atm}$ and factor of 4 low at $15 \mathrm{~atm}$. Propene oxide, a key indicator of propylperoxy isomerization, is produced from the decomposition of the hydroperoxy-propyl radicals whose decomposition rate constant was calculated using QRRK. This reaction shows high sensitivity in the analysis discussed below. Propionaldehyde and acetone are predicted to be at the same order of magnitude as in the experiments. 
Sensitivity analysis was performed by multiplying the rate constant of an individual reaction by a factor of two, computing the final propane concentration at $735 \mathrm{~K}$ and $790 \mathrm{~K}$, and calculating the percent change compared to the baseline case. An positive percent change indicates a decreased overall reaction rate and a negative percent changes indicates an increased overall reaction rate. The temperatures $735 \mathrm{~K}$ and $790 \mathrm{~K}$ represent onset and end of the NTC region at $15 \mathrm{~atm}$, respectively (Fig. 1). The reaction rate constants that exhibited the highest sensitivity are shown in Fig. 4. The reaction with the top sensitivity is the production of propene from hydroperoxy-propyl:

$$
\text { C. }{ }_{3} \mathrm{H}_{6} \mathrm{OOH} \leftrightarrow \mathrm{C}_{3} \mathrm{H}_{6}+\mathrm{HO}_{2}
$$

This reaction (forward direction) has the largest inhibiting effect on the overall oxidation rate and plays a major role producing NTC behavior as previously described in the literature [20]. The new understanding obtained in the present study, as discussed below, is that most of the propene comes from dissociation of hydroperoxy-propyl adduct (Reaction 1), rather than from the chemically-activated reaction:

$$
\mathrm{C}_{3} \mathrm{H}_{7}+\mathrm{O}_{2} \rightarrow \mathrm{C}_{3} \mathrm{H}_{6}+\mathrm{HO}_{2}
$$

The reaction exhibiting the second highest sensitivity is $\mathrm{H}$-atom abstraction from the fuel by $\mathrm{OH}$ radicals. The rate of this reaction is well-known and taken from Droege and Tully [19]. Hydrogen peroxide decomposition gives the third highest sensitivity. This reaction is important in controlling the overall reaction rate at the end of the NTC region $(790 \mathrm{~K}$ ) and has comparatively little effect at the onset of NTC. The high sensitivity shown by

$$
\mathrm{O}_{2} \mathrm{C}_{3} \mathrm{H}_{6} \mathrm{OOH} \rightarrow \mathrm{HOOR}^{\prime} \mathrm{CHO}+\mathrm{OH}
$$

indicates the important role of the addition of $\mathrm{O}_{2}$ to.hydroperoxy-propyl giving $\mathrm{O}_{2} \mathrm{C}_{3} \mathrm{H}_{6} \mathrm{OOH}$ and leading to subsequent reactions. The pressure and temperature dependence of the decomposition rate constant of above reaction was calculated by QRRK.

Analysis of the reaction paths described by the numerical simulations show many interesting features. Several key reactions are in partial equilibrium so that 
their relative concentrations are controlled by thermochemistry. These major reactions include the addition of propyl and hydroperoxy-propyl to $\mathrm{O}_{2}$ :

$$
\begin{gathered}
\mathrm{C}_{3} \mathrm{H}_{7}+\mathrm{O}_{2} \leftrightarrow \mathrm{C}_{3} \mathrm{H}_{7} \mathrm{O}_{2} \\
\mathrm{C}_{3} \mathrm{H}_{6} \mathrm{OOH}+\mathrm{O}_{2} \leftrightarrow \mathrm{O}_{2} \mathrm{C}_{3} \mathrm{H}_{6} \mathrm{OOH} .
\end{gathered}
$$

Careful estimation of thermodynamic parameters for the species in these reactions was important to achieve the proper partial equilibrium. Additionally, reverse rates controlled by thermochemical parameters were important for Reaction 1 that produces propene. Reverse rates computed from thermochemistry were 10-15\% of the forward rates.

One key issue addressed in this study are chemically-activated reactions involving the addition of propyl and hydroperoxy-propyl radicals to molecular oxygen. In the case of propyl radicals, a fraction of the chemically excited adducts formed from the addition reacts to propene and $\mathrm{HO}_{2}$ (Reaction 2). The most rapid rate was found at the end of the NTC region $(770-780 \mathrm{~K})$ where ca. $10 \%$ of the propene is produced by the chemically activated path. The remaining propene (ca. 90\%) is produced through stabilized adducts (Reaction 1). In the case of hydroperoxy-propyl addition to molecular oxygen, the chemically-activated paths contribute less than $0.5 \%$ of the overall addition process. Almost all the molecular addition proceeds through stabilized adducts:

$$
\text { C. } 3 \mathrm{H}_{6} \mathrm{OOH}+\mathrm{O}_{2} \leftrightarrow \mathrm{O}_{2} \mathrm{C}_{3} \mathrm{H}_{6} \mathrm{OOH} \rightarrow \text { products }
$$

The present study demonstrates the importance of a new path for the consumption of the adduct $\mathrm{O}_{2} \mathrm{C}_{3} \mathrm{H}_{6} \mathrm{OOH}$. The adduct can react by two paths, the first of which (Reaction 3) is frequently mentioned in the literature [20]:

$$
\begin{aligned}
.0 O C C C O O H & \rightarrow \mathrm{HOOCCC}=\mathrm{O}+\mathrm{OH} \\
& \rightarrow \mathrm{HOOCC} . \mathrm{COOH} \rightarrow \mathrm{C}=\mathrm{CCOOH}+\mathrm{HO}_{2}
\end{aligned}
$$

(The carbon atoms are assumed to be fully saturated with $\mathrm{H}$ atoms, the dot indicates a radical site on the left, adjacent carbon atom. The above example shows the consumption of one of the three possible $\mathrm{O}_{2} \mathrm{C}_{3} \mathrm{H}_{6} \mathrm{OOH}$ isomers). The second path (Reaction 4) involves abstraction of the $\mathrm{H}$ atom from the non-oxygenated carbon by the peroxy moiety and has been noted recently [12]. Calculations show that the second path accounts for 5-30\% of the consumption (by isomerization) of the $\mathrm{O}_{2} \mathrm{C}_{3} \mathrm{H}_{6} \mathrm{OOH}$ adducts at the start of the NTC region, with the remaining $70-90 \%$ 
consumed by Reaction 3. Reaction 3 accelerates the oxidation process (as seen in Fig. 4) because it produces a reactive $\mathrm{OH}$ radical while Reaction 4 produces a relatively unreactive $\mathrm{HO}_{2}$ radical. It is, therefore, important to include the newlyconsidered path (Reaction 4) to achieve the proper overall rate for propane oxidation.

\section{CONCLUSIONS}

High pressure flow reactor experiments are successfully simulated with a newly developed mechanism for propane oxidation. In the mechanism development, the thermodynamic parameters of the peroxy and hydroperoxy $\mathrm{C}_{3}$ species were carefully estimated. These properties controlled the partial equilibrium of key reactions involving the addition of propyl and hydroperoxy-propyl to molecular oxygen. Chemically-activated reaction paths associated with these additions were also estimated by QRRK/fall-off analysis. In the case of propyl addition to $\mathrm{O}_{2}$, the chemically activated reaction paths contributed about $10 \%$ of the propene production at the end of the NTC region. In the case of hydroperoxypropyl addition to $\mathrm{O}_{2}$, the chemically activated paths contributed less than $0.5 \%$, with almost all the addition proceeding through stabilized adducts. These results indicate that for propane oxidation at 10 and $15 \mathrm{~atm}$ across the NTC region, these chemically activated paths make a minor contribution.

\section{ACKNOWLEDGMENTS}

The authors greatly appreciate valuable discussions with Dr. Henry Curran, Dr. Nick Marinov and Dr. Charles Westbrook of Lawrence Livermore National Laboratory. The experimental work at Drexel University was carried out under ARO contract No. DAAH04-93-G-0042 and NSF grant no. CTS 9213501. The portion of this work at Wichita State University was funded by the National Institute for Aviation Research. The work at LLNL was carried out under the auspices of the U. S. Department of Energy by the Lawrence Livermore National Laboratory under contract No. W-7405-ENG-48. 


\section{REFERENCES}

1. Koert, D.N. and Cernansky, N.P., Meas. Sci. Technol. (formerly J. Phys. E) 3:607$613,1992$.

2. Koert, D.N., Miller, D.L. and Cernansky, N.P. Combust. Flame 96:34-49 (1994).

3. Dagaut, P., Cathonnet, M., Boettner, J.C., and Gaillard, F. Combust. Sci. and Tech. 56:23-63 (1987).

4. Hoffman, J.S., Lee, W., Litzinger, T. A., Santavicca, D. A., and Pitz, W. J., Combust. Sci. Technol. 77:95 (1991).

5. Cathonnet, M., Boettner, J.C., and James, H., Eighteenth Symposium (International) Combustion, The Combustion Institute, Pittsburgh, 1981, p. 903.

6. Wilk, R. D., Cernansky, N. P., and Cohen, R. S. Combust. Sci. and Tech., 49:41-78 (1986).

7. Pitz, W. J., Westbrook, C. K., and Leppard, W. R., "Autoignition Chemistry of $\mathrm{C}_{4}$ Olefins Under Motored Engine Conditions: A Comparison of Experimental and Modeling Results," SAE Transactions, SAE paper SAE-912315 (1991).

8. Ritter, E. R. and Bozzelli, J. W. Int. J. Chem. Kinet. 23:767(1991).

9. Lay, T., Bozzelli, J. W., Dean, A. M., and Ritter, E. R. J. Phys. Chem. 99:14514 (1995).

10. Lay, T., Krasnoperov, L., Venanzi, C., and Bozzelli, J. J. Phys. Chem., In print, 1996.

11. Nick Marinov, N. M. and Malte, P. C. Int. J. Chem. Kin. 27:957 (1995).

12. Bozzelli, J.W. and Pitz, W.J. Twenty-Fifth International Symposium on Combustion, The Combustion Institute, Pittsburgh, PA, 1994, p. 783-791.

13. Dorofeeva, O. V., Gurvich, L. V., and Jorish, V. S. J. Phys. Chem. Ref. Data 15:437-464 (1986).

14. Bozzelli, J.W., and Dean, A.M. J. Phys. Chem. 94:3313 (1990).

15. Evans, M. G. and Polanyi, M. Trans. Faraday Soc. 34:11 (1938). 
16. Ritter, E. R., and Bozzelli, J. W., Chemical and Physical Processes in Combustion, The Combustion Institute, Pittsburgh, PA, 1993, \#103, p. 459.

17. Dean, A. M., J. Phys. Chem. 89:4600 (1985).

18. Dean, A. M., Bozzelli, J. W., Ritter, J. W. Combust. Sci. Tech. 80:63-85 (1991).

19. Droege, A.T. and Tully, F.P., J. Phys. Chem. 90:1949 (1986).

20. Benson, S. W. Prog. Energy Combust. Sci. 7:125-134 (1981). 
FIGURE CAPTIONS

Figure 1. Comparison of the experimental and calculated fuel consumed: A. 10 atm. B. $15 \mathrm{~atm}$

Figure 2. Comparison of the experimental and calculated species concentrations at $10 \mathrm{~atm}$. (Experimental results are on the left and calculated results on the right).

Figure 3. Comparison of the experimental and calculated species concentrations at $15 \mathrm{~atm}$. . (Experimental results are on the left and calculated results on the right).

Figure 4. Sensitivity results at 15 atm. ( $\mathrm{RH}$ is propane, $\mathrm{R}$ is propyl, $\mathrm{RO} 2$ is $\mathrm{CH}_{3} \mathrm{O}_{2}$, $\mathrm{C}_{2} \mathrm{H}_{5} \mathrm{O}_{2}$ and $\mathrm{C}_{3} \mathrm{H}_{7} \mathrm{O}_{2}, \mathrm{XO} 2$ is $\mathrm{HO}_{2}$ and $\mathrm{CH}_{3} \mathrm{O}_{2}, \mathrm{c}-\mathrm{C} 3 \mathrm{H} 6 \mathrm{O}$ is a $\mathrm{C}_{3}$ cyclic ether, and $\mathrm{HOOR}{ }^{\prime} \mathrm{CHO}$ is a $\mathrm{C}_{3}$ ketohydroperoxide.) 
Table 1: Thermochemical Properties of Important Species

\begin{tabular}{|c|c|c|}
\hline Species & $\Delta \mathrm{H}_{\mathrm{f} 298}^{\circ}$ & $\mathrm{S}_{298}$ \\
\hline $\mathrm{HO}_{2}$ & 3.80 & 54.73 \\
\hline $\mathrm{CH}_{3} \mathrm{OO}$. & 4.50 & 65.84 \\
\hline C. $\mathrm{H}_{2} \mathrm{OOH}$ & 14.80 & 67.53 \\
\hline $\mathrm{CH}_{3} \mathrm{OOH}$ & -31.60 & 65.62 \\
\hline CCOOO. & -4.99 & 75.75 \\
\hline C.COOH & 7.91 & 78.94 \\
\hline CC.OOH & 2.81 & 79.35 \\
\hline. $\mathrm{OOCCOOH}$ & -25.68 & 94.82 \\
\hline $\mathrm{HOOC.COOH}$ & -17.88 & 98.42 \\
\hline $\mathrm{CCOOH}$ & -41.09 & 75.53 \\
\hline $\mathrm{HOOCCOOH}$ & -61.78 & 94.60 \\
\hline C.CCOOH & 2.98 & 89.74 \\
\hline CC.COOH & 0.33 & 89.39 \\
\hline CCC.OOH & -2.12 & 88.77 \\
\hline CCCOO. & -9.92 & 85.17 \\
\hline $\mathrm{C}_{2} \mathrm{COO}$ & -12.48 & 82.30 \\
\hline $\mathrm{C}_{2} \cdot \mathrm{COOH}$ & 0.42 & 86.88 \\
\hline $\mathrm{C}_{2} \mathrm{C} . \mathrm{OOH}$ & -7.08 & 88.06 \\
\hline HOOC.CCOOH & -30.61 & 104.24 \\
\hline $\mathrm{HOOCC.COOH}$ & -20.36 & 108.46 \\
\hline $\mathrm{HOOC.CCOOH}$ & -22.81 & 107.84 \\
\hline $\mathrm{CC}(\mathrm{OO}.) \mathrm{COOH}$ & -32.37 & 101.38 \\
\hline $\mathrm{CC}(\mathrm{OOH}) \mathrm{COO}$ & -32.37 & 101.38 \\
\hline C.C(OOH) $\mathrm{COOH}$ & -19.47 & 105.95 \\
\hline C. $(\mathrm{OOH}) \mathrm{COOH}$ & -26.97 & 107.14 \\
\hline $\mathrm{CC}(\mathrm{OOH}) \mathrm{C} . \mathrm{OOH}$ & -24.57 & 104.98 \\
\hline $\mathrm{CCCOOH}$ & -46.02 & 84.95 \\
\hline $\mathrm{C}_{2} \mathrm{COOH}$ & -48.58 & 82.08 \\
\hline $\mathrm{HOOCCCOOH}$ & -66.71 & 104.02 \\
\hline $\mathrm{CC}(\mathrm{OOH}) \mathrm{COOH}$ & -68.47 & 101.16 \\
\hline $\mathrm{CC}(=\mathrm{O}) \mathrm{COOH}$ & -71.31 & 90.93 \\
\hline $\mathrm{CC}(\mathrm{OOH}) \mathrm{C}=\mathrm{O}$ & -67.63 & 89.37 \\
\hline $\mathrm{HOOCCC}=\mathrm{O}$ & -65.46 & 92. \\
\hline
\end{tabular}

Notes: Dot denotes radical site on atom to left.

Units: $\Delta \mathrm{H}_{\mathrm{f} 298}^{\circ}, \mathrm{kcal} / \mathrm{mole}^{\circ} \mathrm{S}_{298} \mathrm{cal} / \mathrm{mol}-\mathrm{K}$. 
Table 2: $\mathrm{RO}_{2}$ Isomerization Rate Constants $\left(\mathrm{RO}_{2} \Rightarrow \mathrm{R}^{\prime} \mathrm{OOH}\right)$ $\left(\mathrm{k}=\mathrm{AT}^{\mathrm{N}} \exp \left(-\mathrm{E}_{\mathrm{a}} / \mathrm{RT}\right)\right.$, rate per $\mathrm{H}$ atom)

\begin{tabular}{|c|c|c|c|c|c|}
\hline Ring Size & Site & $\begin{array}{c}\mathrm{A} \\
{\left[\mathrm{sec}^{-1}\right]}\end{array}$ & $\mathrm{N}$ & $\begin{array}{c}\mathrm{E}_{\mathrm{a}} \\
{[\mathrm{kcal} / \mathrm{mole}]}\end{array}$ & $\mathrm{RO}_{2}$ \\
\hline \multirow[t]{2}{*}{5} & primary & $1.29 \mathrm{E}+09$ & 1 & 28.8 & $\mathrm{C}_{2} \mathrm{COO}$. \\
\hline & secondary & $5.70 \mathrm{E}+08$ & 1 & 26.7 & CCCOO. \\
\hline 6 & primary & $4.54 \mathrm{E}+07$ & 1 & 22.9 & CCCOO. \\
\hline
\end{tabular}



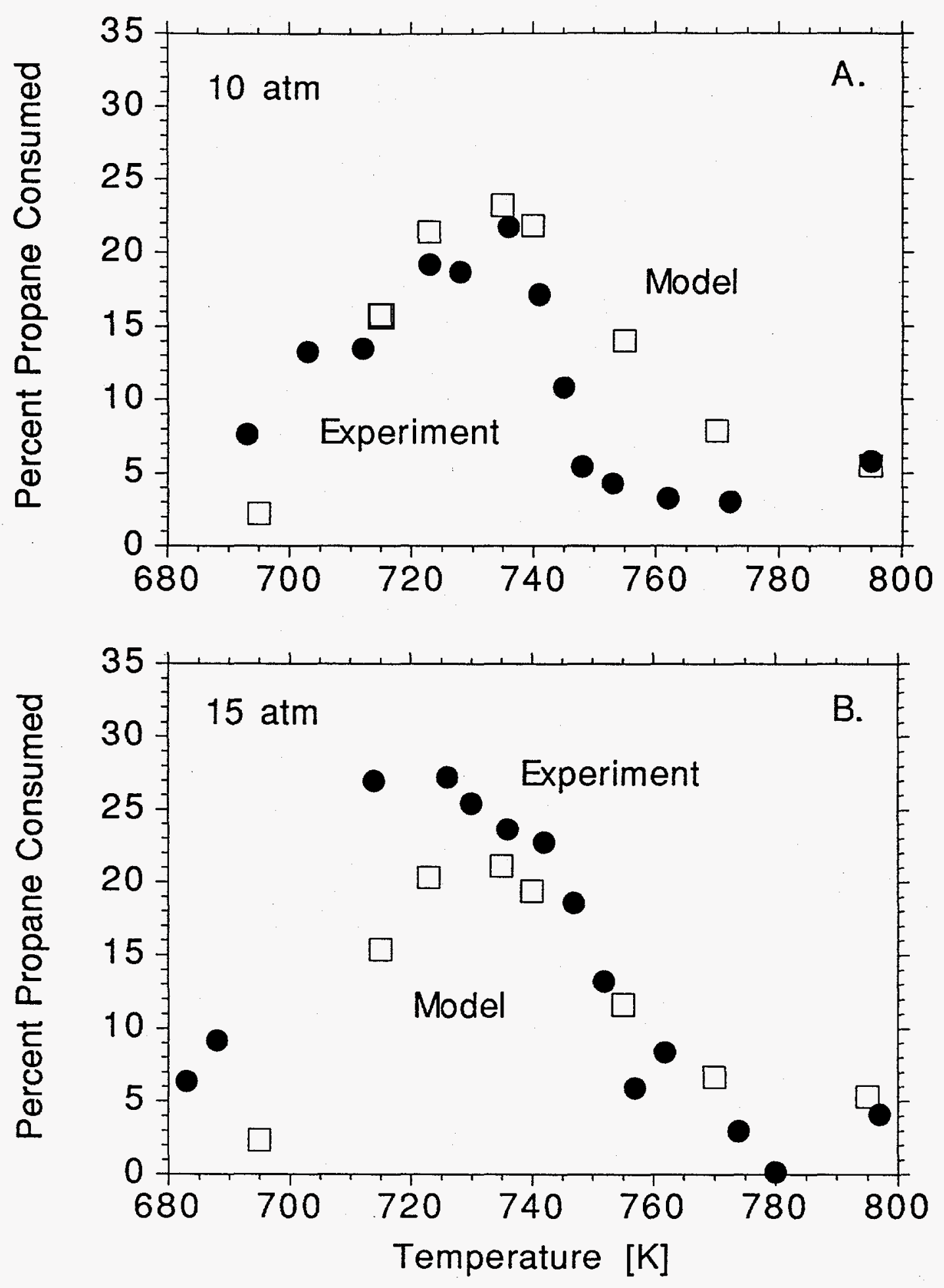

Fig. 1 

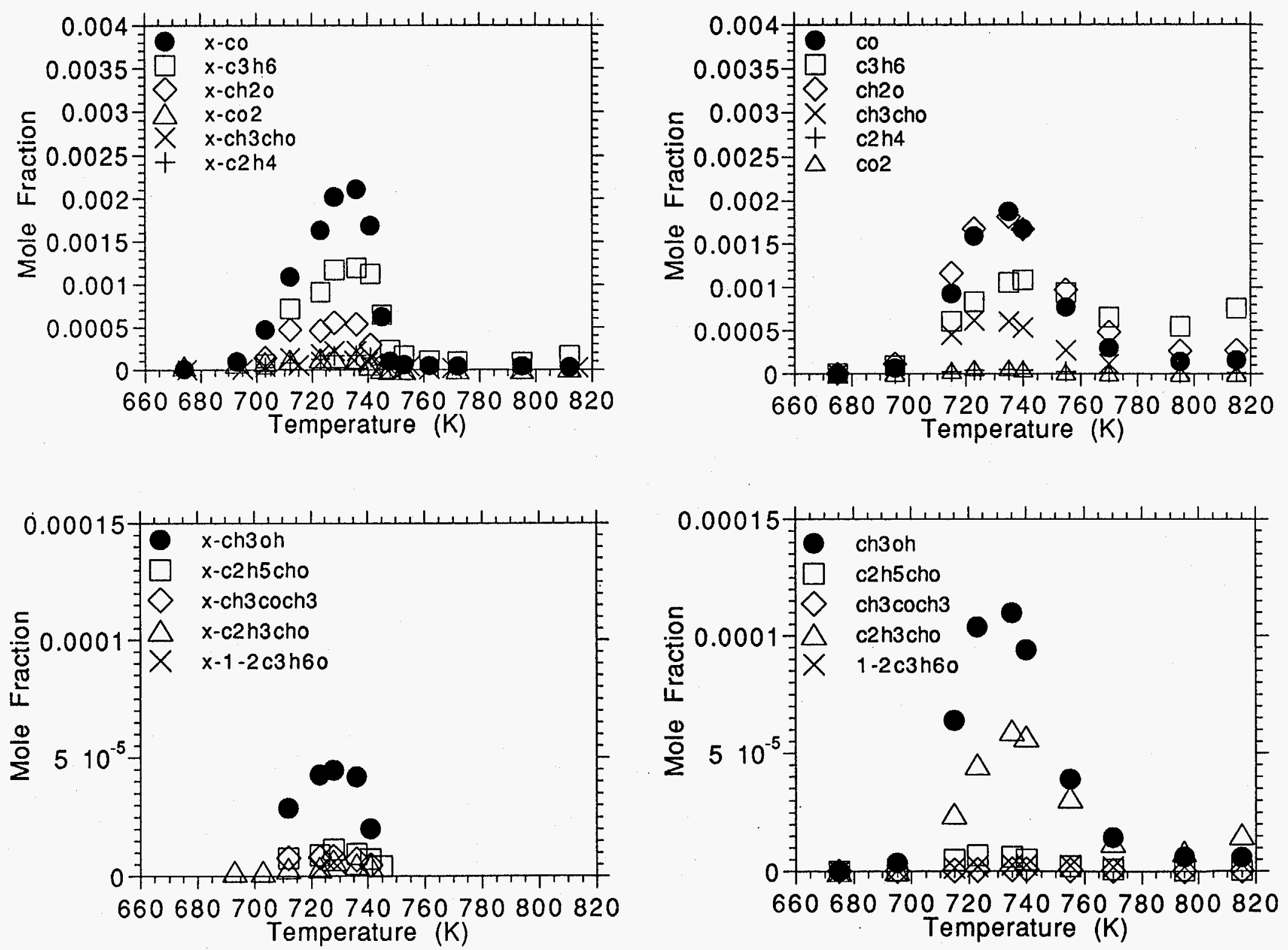

Fig. 2 

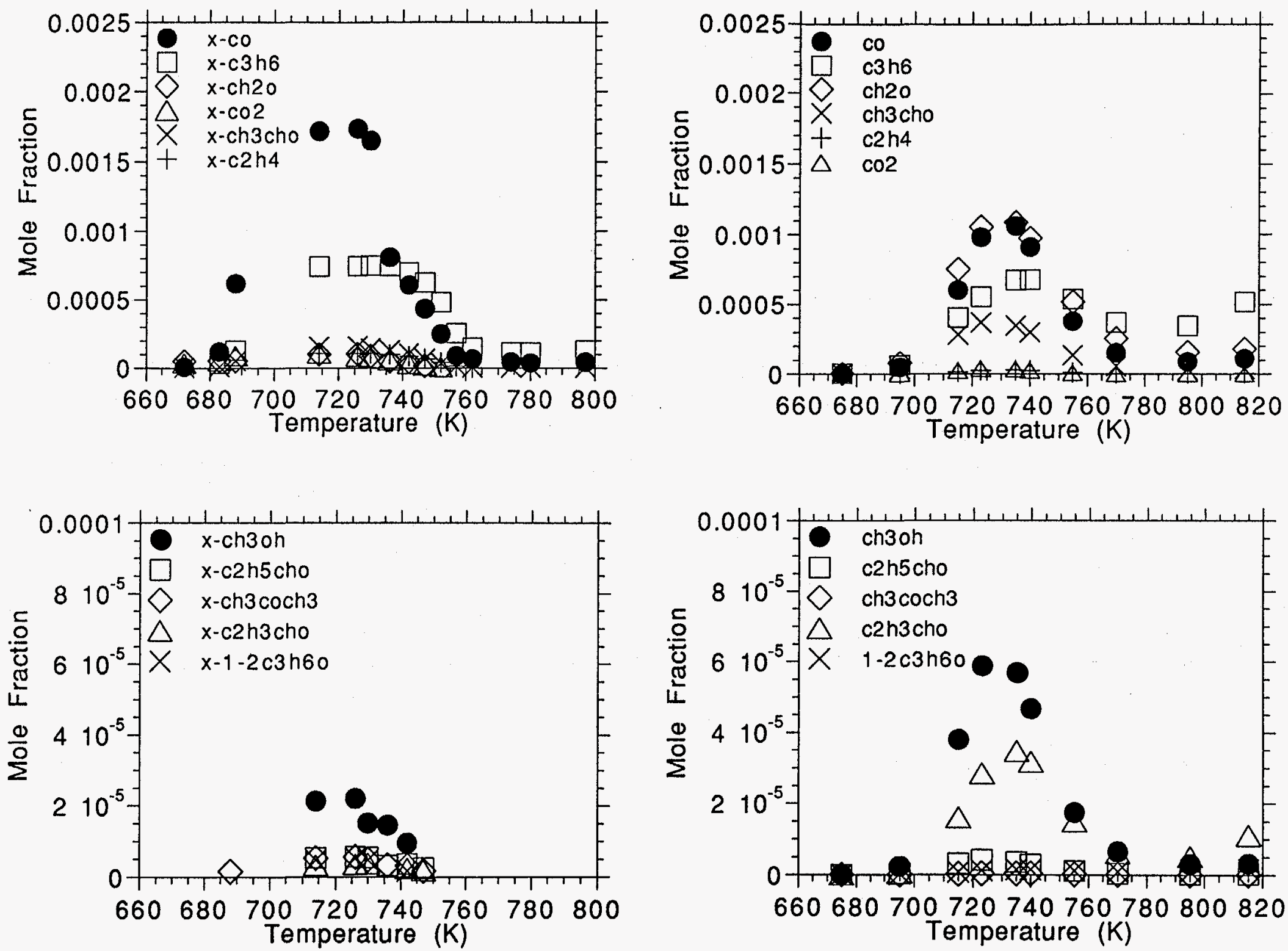

Fig. 3 


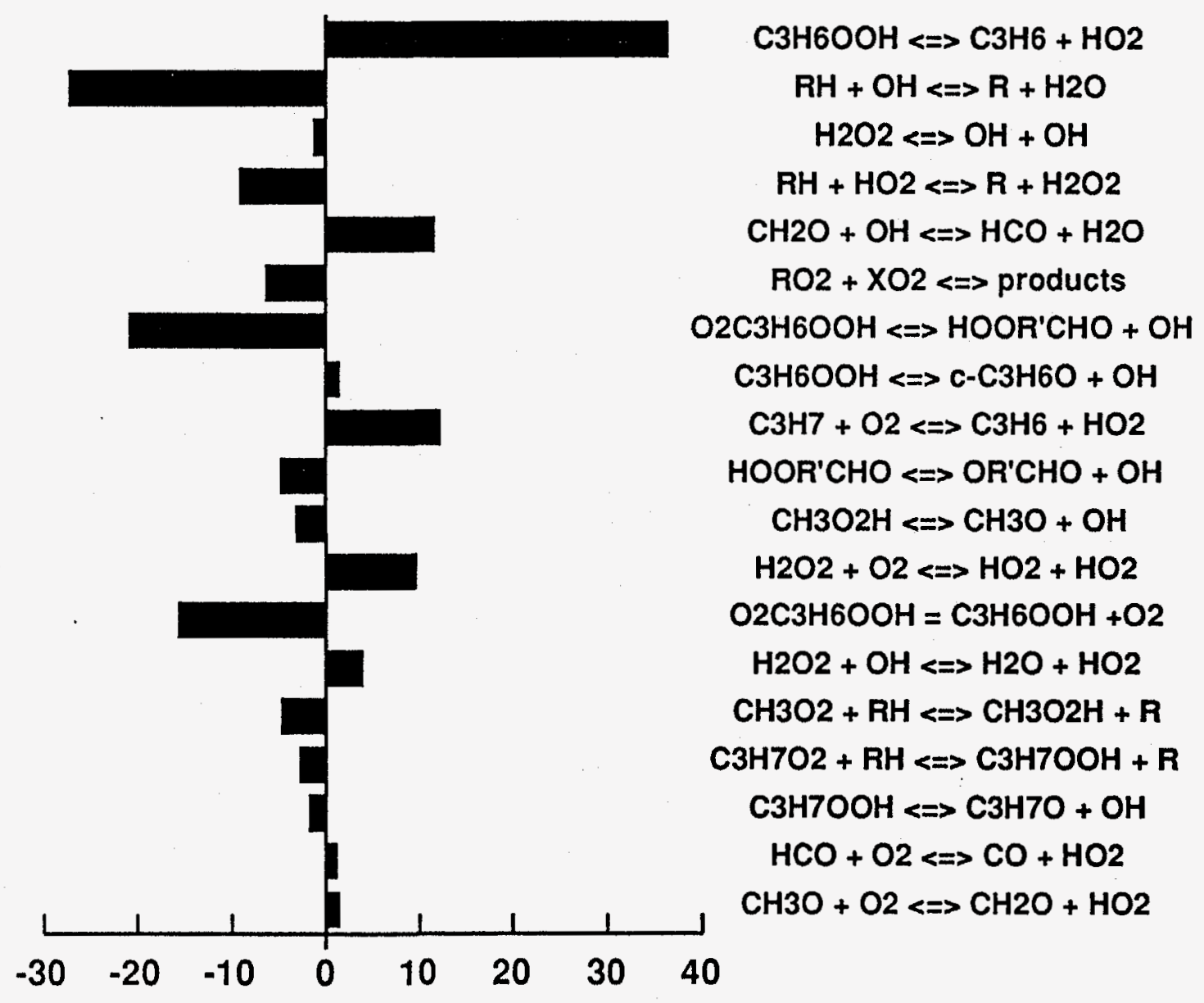

\% Change in $\mathrm{C} 3 \mathrm{H} 8$ at $735 \mathrm{~K}$

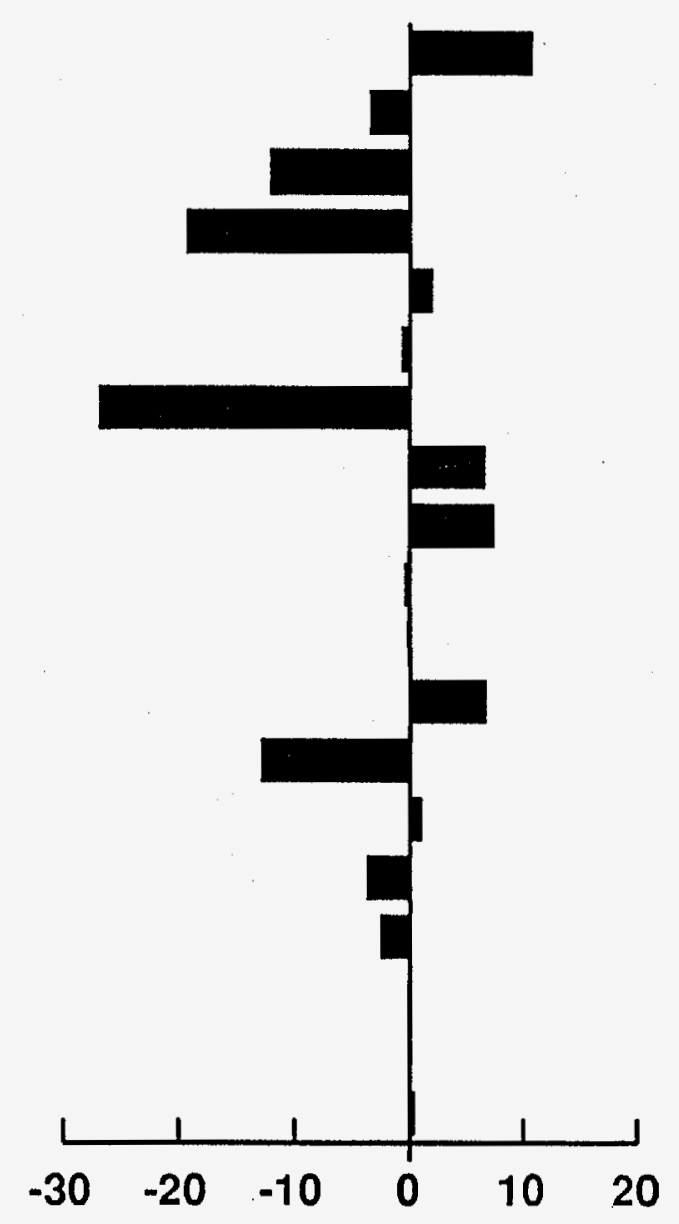

$\%$ Change in $\mathrm{C} 3 \mathrm{H} 8$ at $790 \mathrm{~K}$ 